\title{
Microstructure and Properties of Ultrafine Cemented Carbides Prepared by Microwave Sintering of Nanocomposites
}

\author{
Yanju Qian and Zhiwei Zhao* \\ College of Materials Science and Engineering, Henan University of Technology, Zhengzhou 450001, China; \\ qianyanju001@163.com \\ * Correspondence: zhiwei_zhao@haut.edu.cn; Tel.: +86-371-6775-8730
}

Received: 4 May 2020; Accepted: 10 June 2020; Published: 13 June 2020

\begin{abstract}
Ultrafine cemented carbides were prepared by microwave sintering, using $\mathrm{WC}-\mathrm{V}_{8} \mathrm{C}_{7^{-}}$ $\mathrm{Cr}_{3} \mathrm{C}_{2}$-Co nanocomposites as a raw material. The effects of sintering temperature and holding time on the microstructure and mechanical properties of cemented carbides were studied. The results show that the ultrafine cemented carbides prepared at $1300{ }^{\circ} \mathrm{C}$ for $60 \mathrm{~min}$ have good mechanical properties and a good microstructure. The relative density, Vickers hardness, and fracture toughness of the specimen reach the maximum values of $99.79 \%, 1842 \mathrm{~kg} / \mathrm{mm}^{2}$ and $12.6 \mathrm{MPa} \cdot \mathrm{m}^{1 / 2}$, respectively. Tungsten carbide (WC) grains are fine and uniformly distributed, with an average grain size of $300-500 \mathrm{~nm}$. The combination of nanocomposites, secondary pressing, and microwave sintering can significantly reduce the sintering temperature and inhibit the growth of WC grains, thus producing superfine cemented carbides with good microstructure and mechanical properties.
\end{abstract}

Keywords: cemented carbide; microwave sintering; nanocomposite; microstructure; mechanical properties

\section{Introduction}

Cemented carbides are one of the most widespread powder metallurgy products worldwide. The reason for this is that, compared with other cutting materials (such as diamond or high-speed steel), they have an excellent combination of hardness and toughness [1,2]. With rapid industrial development, the design and performance requirements imposed on cemented carbide tools are constantly becoming more onerous, and the performance of the ordinary grain size of cemented carbide cannot fully meet modern industrial demands. Ultrafine (nanocrystalline) cemented carbides have, in theory, superior mechanical properties to conventional coarse-grained cemented carbides [3,4], such as hardness, wear resistance, and flexural strength. Some studies have shown that when the content of Co-phase is constant and when the WC grain size reaches ultrafine or nanocrystalline, the hardness and toughness of cemented carbides are improved [5,6]. When the WC grain size is less than $500 \mathrm{~nm}$, the hardness and toughness of the cemented carbides are greatly improved. Therefore, the development of ultrafine or nanocrystalline cemented carbides with high hardness and high strength has become a key research issue among those working with cemented carbide materials [7].

In recent years, scholars have adopted many new technologies and methods to improve the mechanical properties of cemented carbides, prolong the service life of cemented carbide tools, and reduce the production costs thereof [8-10]. The key to the preparation of ultrafine cemented carbides is the effective inhibition of WC grains during the preparation and sintering of the powdered raw materials [11,12]. Therefore, grain growth inhibitors (GGIs) and rapid sintering methods were used in ultrafine cemented carbides to mitigate and suppress the growth of grains at elevated sintering temperatures [13]. 
In this experiment, $\mathrm{WC}-\mathrm{V}_{8} \mathrm{C}_{7}-\mathrm{Cr}_{3} \mathrm{C}_{2}$-Co nanocomposites were used as raw materials, and ultrafine tungsten carbide-based cemented carbides were prepared by secondary pressing (moulding and cold isostatic pressing) and microwave sintering. Since the raw materials are nano-powders, with a high specific surface area, a large contact area between the particles, many interfacial atoms and a high atomic diffusion coefficient in the interfacial region, such nano-materials exhibit high chemical activity. In addition, nanocomposite GGIs can inhibit WC grain growth. Therefore, the sintering temperature can be lowered, the reaction time can be shortened, and the abnormal growth of the WC crystal grains can be effectively inhibited [14-16]. Secondary pressing (moulding and cold isostatic pressing) is conducive to obtaining higher density green bodies, which is conducive to the rapid sintering and densification of composites. Furthermore, as a rapid sintering technology with a special mechanism of action, microwave sintering has received more attention in recent years. Microwaves refer to electromagnetic waves ranging from $300 \mathrm{MHz}(1 \mathrm{~m}$ wavelength) to $300 \mathrm{GHz}$ (1 mm wavelength) [17]. Microwave sintering has many advantages that are difficult to achieve with conventional heating, such as high energy efficiency, no pollution, a low sintering temperature, uniform microstructure of materials thus produced, and materials that can acquire special structures or properties $[18,19]$. In this study, $\mathrm{WC}-\mathrm{V}_{8} \mathrm{C}_{7}-\mathrm{Cr}_{3} \mathrm{C}_{2}$-Co nanocomposites were used as raw materials to prepare ultrafine cemented carbides by using microwave sintering technology and secondary pressing (moulding and cold isostatic pressing). The effects of sintering temperature and holding time on the microstructure and mechanical properties of the alloy were investigated.

\section{Materials and Methods}

The nano-WC (purity $>99.9 \%$, average particle size $<200 \mathrm{~nm}$, Shanghai Shuitian Material Technology Co., Ltd., Shanghai, China), nano- $\mathrm{V}_{8} \mathrm{C}_{7}$ (purity $>99.9 \%$, average particle size $<200 \mathrm{~nm}$, Shanghai Shuitian Material Technology Co., Ltd.), nano- $\mathrm{Cr}_{3} \mathrm{C}_{2}$ (purity $>99.9 \%$, average particle size $<100 \mathrm{~nm}$, Shanghai Shuitian Material Technology Co. Ltd.) and nano-Co (purity $>99.9 \%$, average particle size $<50 \mathrm{~nm}$, Shanghai Shuitian Material Technology Co. Ltd.) powders were used as raw materials. According to a certain ratio (WC: $\mathrm{V}_{8} \mathrm{C}_{7}: \mathrm{Cr}_{3} \mathrm{C}_{2}: \mathrm{Co}=89.5 \%: 0.25 \%: 0.25 \%: 10 \%$ ), the raw materials were mixed in a planetary ball mill (QM-3SP2, Nanjing Laibe Industrial Co., Ltd., Nanjing, China) for ball milling (150 rpm), at a ball to powder weight ratio of 5:1, wherein the ball milling medium was anhydrous ethanol (liquid-solid ratio $350 \mathrm{~mL} / \mathrm{kg}$ ). After being milled for $8 \mathrm{~h}$, the mixture was dried at $90{ }^{\circ} \mathrm{C}$ for $24 \mathrm{~h}$. An appropriate amount of paraffin was added to these materials and mixed evenly. The mixed powders (after stuffing) were pressed into $6 \mathrm{~mm} \times 6 \mathrm{~mm} \times 28 \mathrm{~mm}$ cuboid specimens using a hydraulic press. They were then further pressed using a cold isostatic press, to increase the density of the green body. The pressed specimens were vacuum-dried at $100^{\circ} \mathrm{C}$ for $24 \mathrm{~h}$. Finally, the dried specimens were sintered in a microwave sintering furnace (RWS-3, Hunan Zhongsheng Thermal Energy Technology Co., Ltd.) at sintering temperatures of 1100, 1200, 1300, and $1400{ }^{\circ} \mathrm{C}$, for holding times of 20,40,60, and $80 \mathrm{~min}$. Before sintering, the sintering furnace was pumped out to a vacuum of $1 \times 10^{-2} \mathrm{~Pa}$, and then argon gas was introduced to form a protective atmosphere at a flow rate of $20 \mathrm{~mL} / \mathrm{min}$. The heating and cooling rates were $10-50^{\circ} \mathrm{C} / \mathrm{min}$ and $8-30^{\circ} \mathrm{C} / \mathrm{min}$, respectively, and subsequent dewaxing was conducted at $610^{\circ} \mathrm{C}$ for $30 \mathrm{~min}$.

The phase composition of the specimen was measured using a D8 AA25 X-ray single crystal diffractometer (Bruker, Germany) with $\mathrm{Cu}-\mathrm{K}_{\alpha}$ radiation in the range $20^{\circ} \leq 2 \theta \leq 90^{\circ}$. The microstructure and grain size of the specimens were observed by INSPECT F50 scanning electron microscopy (FEI, Hillsboro, OR, USA). The sintered specimens were polished with diamond paste before scanning electron microscopy. The specimen density was measured by a digital solid densitometer using the Archimedes method. The hardness of the specimen was measured using an FM-700 Vickers microhardness tester (Toshiba Teli, Tokyo, Japan) under a load of $1 \mathrm{kgf}$ and loading (displacement-controlled) rate of $50 \mu \mathrm{m} / \mathrm{s}$. Indentation fracture toughness $K_{\mathrm{IC}}$ was estimated by applying the Palmqvist model to the cracks generated by indentation, using the Shetty equation [20]. 


\section{Results and Discussion}

Figure 1 shows the X-ray diffraction (XRD) patterns of the raw materials and the specimens sintered at different temperatures for $40 \mathrm{~min}$.

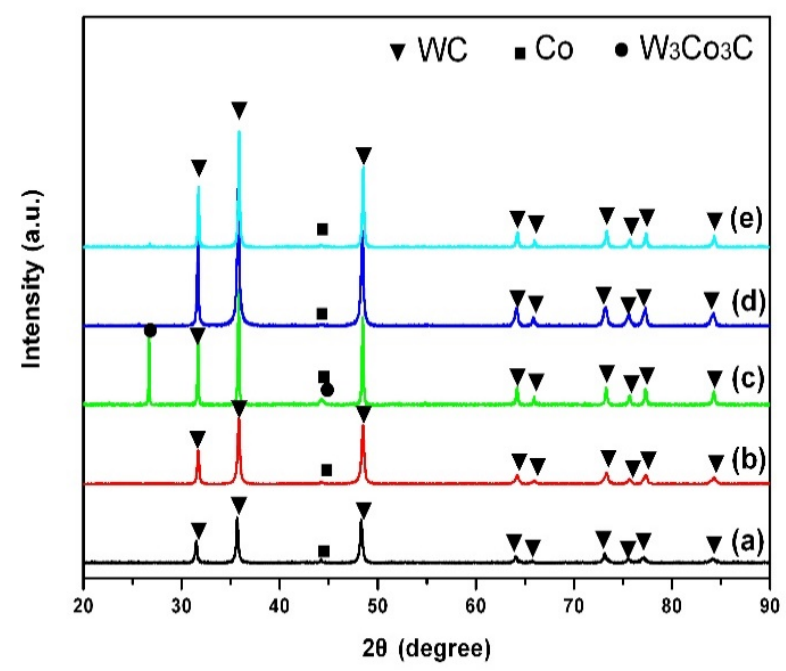

Figure 1. XRD patterns of the composite powders and the specimens sintered at different temperatures for $40 \mathrm{~min}$ : (a) composite powders; (b) $1100^{\circ} \mathrm{C}$; (c) $1200^{\circ} \mathrm{C}$; (d) $130{ }^{\circ} \mathrm{C}$; (e) $1400{ }^{\circ} \mathrm{C}$.

As shown in Figure 1a, the diffraction peaks of the composite powders are mainly composed of WC and Co-phases, and there are no diffraction peaks representing either $\mathrm{V}_{8} \mathrm{C}_{7}$ or $\mathrm{Cr}_{3} \mathrm{C}_{2}$. This is mainly because the amount of grain inhibitors added in this experiment was small (a mass percentage of $0.5 \%$ ) and not within the detection range of the $\mathrm{X}$-ray diffractometer (mass percentage $>1 \%$ ). When the sintering temperature is $1100{ }^{\circ} \mathrm{C}$, the product is mainly composed of WC, and the diffraction peak intensity of the Co-phase is very weak (Figure $1 \mathrm{~b}$ ). This indicates that a liquid phase has appeared in the specimen sintered at $1100{ }^{\circ} \mathrm{C}$, and some WC begins to dissolve in the liquid Co, resulting in the reduction in Co content. Compared with traditional sintering methods [21,22], the liquid phase can appear at a lower sintering temperature. This is mainly because microwave sintering is rapid and relies on a unique heating mechanism. This method is a new sintering method, which uses the dielectric loss of materials to absorb microwave energy directly through the interaction between the microwave and material particles (molecules or ions). In addition, the microwave field can enhance the ionic conductivity. The high-frequency electric field can promote the migration of charged vacancies in the grain surface, thus resulting in plastic deformation, similar to diffusion creep, and promoting sintering [23]. With the increase in sintering temperature, an $\eta$-phase $\mathrm{W}_{3} \mathrm{Co}_{3} \mathrm{C}$ occurs when the sintering temperature is $1200{ }^{\circ} \mathrm{C}$ (Figure 1c). This is mainly because, with the increase in sintering temperature, a large amount of WC dissolves in the Co solution and a small amount of the $\mathrm{W}_{3} \mathrm{Co}_{3} \mathrm{C}$ phase dissolves and precipitates. When the sintering temperature is $1300{ }^{\circ} \mathrm{C}$, the reaction products mainly consist of $\mathrm{WC}$, and the $\mathrm{W}_{3} \mathrm{Co}_{3} \mathrm{C}$ phase disappears (Figure 1d). Moreover, the diffraction peak representing $\mathrm{WC}$ has a higher intensity than that at $1200{ }^{\circ} \mathrm{C}$, mainly due to the decomposition of the $\mathrm{W}_{3} \mathrm{Co}_{3} \mathrm{C}$ phase at this temperature, and the high solubility of nano-inhibitors $\mathrm{V}_{8} \mathrm{C}_{7}$ and $\mathrm{Cr}_{3} \mathrm{C}_{2}$ in $\mathrm{Co}$ solution. This hinders the dissolution of WC in Co, so that the diffraction peak of WC has a high intensity [24]. When the sintering temperature is $1400{ }^{\circ} \mathrm{C}$, the composition of the reaction product remains unchanged, but the diffraction peak of WC becomes sharper (Figure 1e). This is mainly because, when the temperature is too high, the solubility of the nano-inhibitor in the Co liquid reaches saturation, and it is difficult to inhibit the dissolution and growth of the WC particles in the Co liquid. This results in the increase in WC grain size and the narrowing of its diffraction peak.

Figure 2 shows the XRD patterns of the specimens sintered at $1300{ }^{\circ} \mathrm{C}$ for different holding times. As shown in Figure 2, the specimens are mainly composed of WC and contain a small amount of 
Co-phase. As shown in Figure 2, the diffraction peaks of WC gradually shift to smaller angles with increased holding time. This is mainly due to the increase in the interplanar spacing and the decrease of the diffraction angles of WC with increased holding time [25].

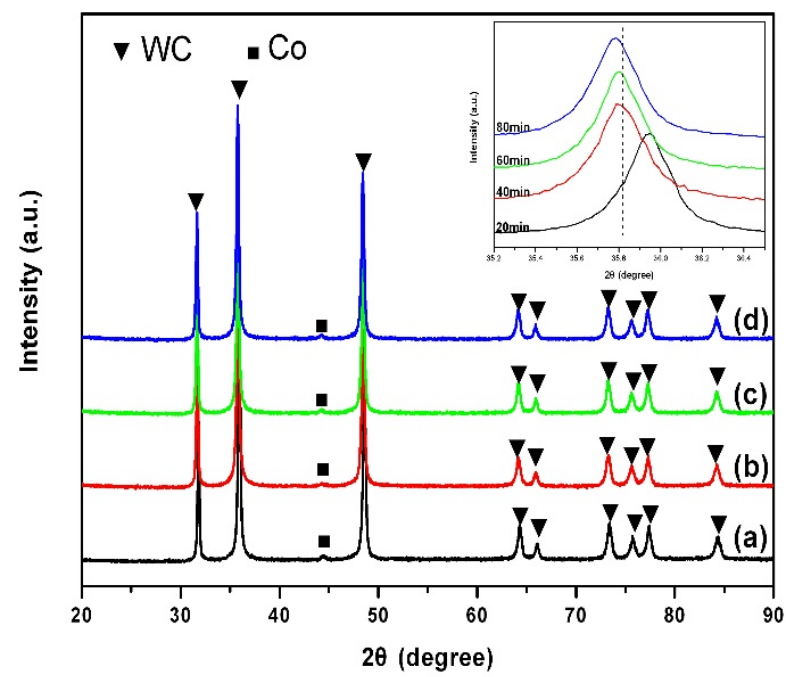

Figure 2. XRD patterns of the specimens sintered at $1300{ }^{\circ} \mathrm{C}$ for different holding times: (a) 20 min; (b) $40 \mathrm{~min}$; (c) $60 \mathrm{~min}$; (d) $80 \mathrm{~min}$.

To observe the surface morphology and pore distribution of the sintered specimens, scanning electron microscopy (SEM) measurements were conducted on specimens prepared at different sintering temperatures and holding times (Figure 3; Figure 4).
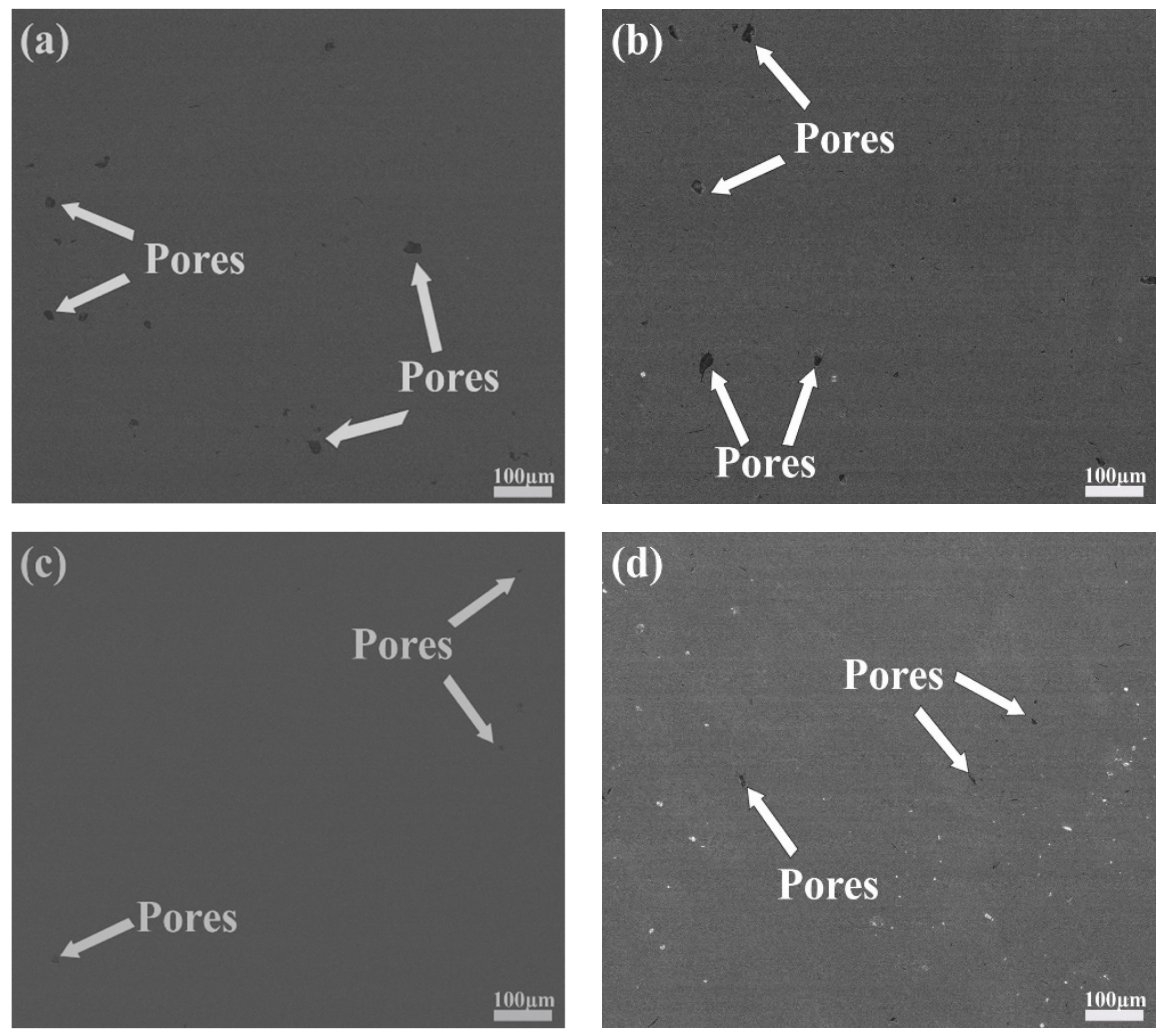

Figure 3. SEM images of ultrafine cemented carbides sintered at different temperatures for 40 min: (a) $1100{ }^{\circ} \mathrm{C}$; (b) $1200{ }^{\circ} \mathrm{C}$; (c) $1300{ }^{\circ} \mathrm{C}$; (d) $1400{ }^{\circ} \mathrm{C}$. 
As shown in Figure 3a, when the sintering temperature is $1100{ }^{\circ} \mathrm{C}$, there are many pores on the surface of the specimen (the residual porosity is $8.36 \%$ ), most of which are $5-50 \mu \mathrm{m}$ in size. With the increase in the sintering temperature, the number and size of the voids on the surface of the specimens decrease gradually. When the sintering temperature is $1300{ }^{\circ} \mathrm{C}$, the specimen contains fewer pores and these are smaller (the residual porosity is $0.93 \%$ ), as shown in Figure 3c. This indicates that the grain size of WC can be effectively inhibited at the sintering temperature of $1300{ }^{\circ} \mathrm{C}$, which is beneficial to the rearrangement and densification of the particles, thus reducing the number and size of the pores, and improving the mechanical properties of the specimen. It can be seen in Figure 4 that the trend in the surface structure of the specimens under different holding time conditions is similar to that seen in Figure 3. When the holding time is $60 \mathrm{~min}$, the number of pores on the surface of the specimen is lower (the residual porosity is $0.18 \%$ ), the pores are smaller, and the microstructure of the specimen is relatively uniform, as shown in Figure 4c.
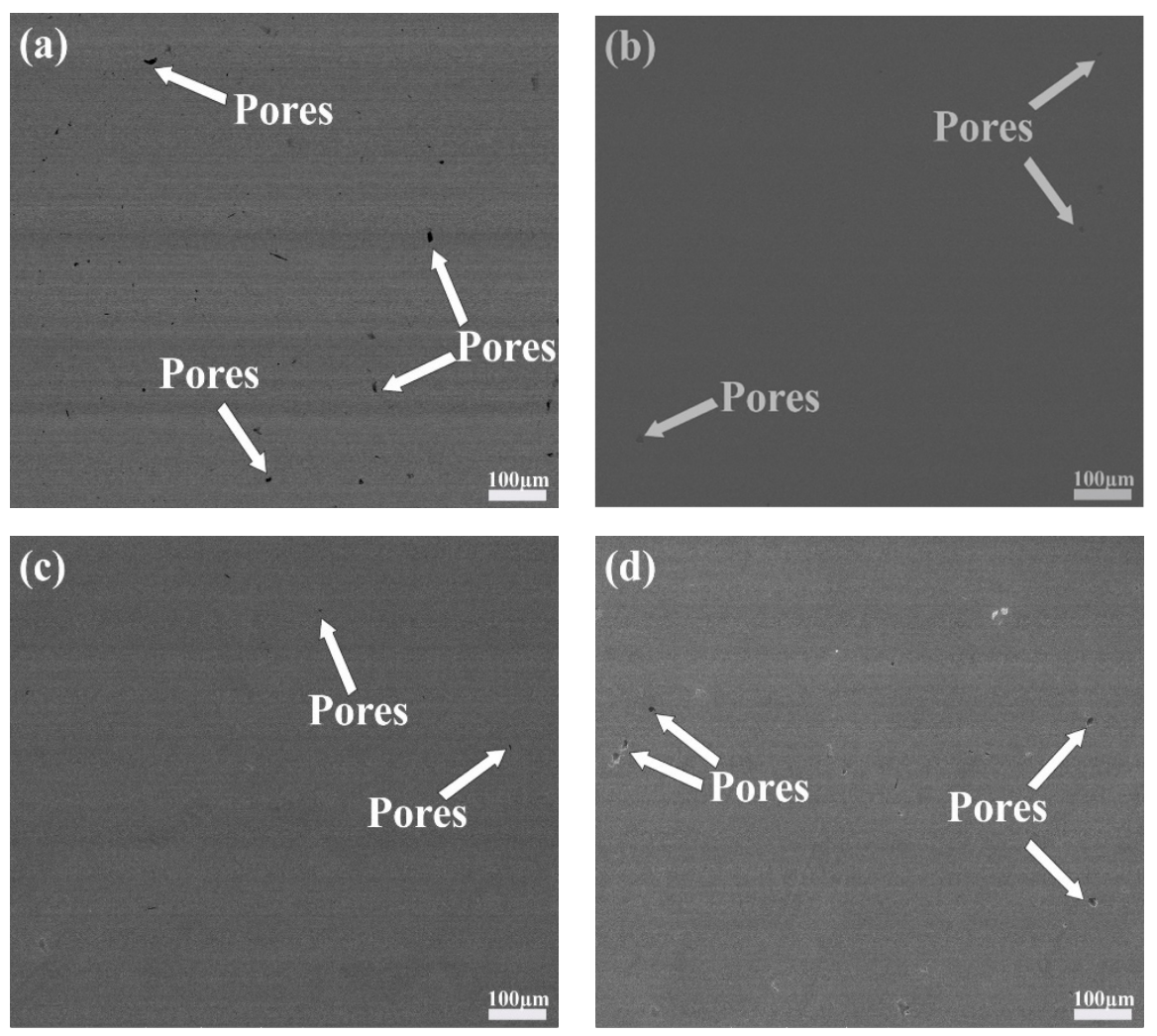

Figure 4. SEM images of ultrafine cemented carbides sintered at $1300{ }^{\circ} \mathrm{C}$ for different holding times: (a) $20 \mathrm{~min}$; (b) $40 \mathrm{~min}$; (c) $60 \mathrm{~min}$; (d) $80 \mathrm{~min}$.

Figure 5 shows the SEM images of the composite powders and specimens sintered at different temperatures for $40 \mathrm{~min}$. As shown in Figure 5a, the particles are spherical or quasi-spherical, and the average particle size is about $200 \mathrm{~nm}$; however, a small amount of agglomeration occurs after ball-milling. This is mainly due to the small grain size of the raw materials, their high specific surface area, and high activity. After high-energy ball-milling, a small amount of soft agglomeration readily occurs [26]. As shown in Figure 5b,c, the distribution of binder phase Co is not uniform at 1100 and $1200{ }^{\circ} \mathrm{C}$. This shows that WC is dissolving and becoming rearranged in the Co-phase, which leads to the uneven distribution of the Co-phase. When the sintering temperature is $1300{ }^{\circ} \mathrm{C}, \mathrm{WC}$ grains are polygonal or spherical, with an average size of about $500 \mathrm{~nm}$, and these are uniformly distributed in the Co-phase, as shown in Figure 5d. When the sintering temperature is $1400{ }^{\circ} \mathrm{C}$, the $\mathrm{WC}$ grains increase in size, showing quadrilateral or polygonal forms, and the average grain size is about $1 \mu \mathrm{m}$ 
(Figure 5e). This is mainly due to the dissolution, growth, and re-precipitation of the WC particles with increasing temperature, resulting in the increase in grain size.
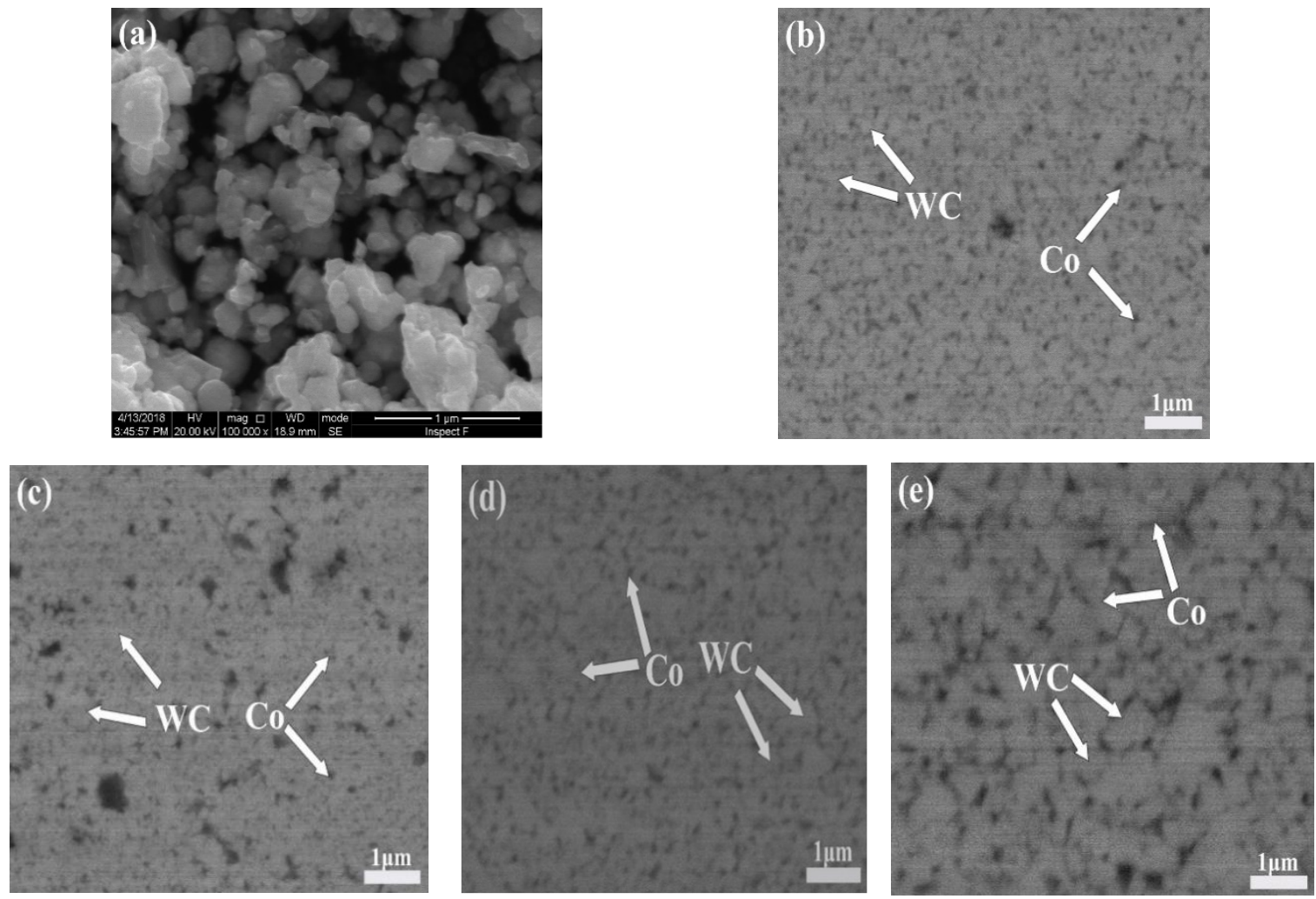

Figure 5. SEM images of (a) the composite powders; (b-e) specimens sintered at different sintering temperatures for $40 \mathrm{~min}$ (BSE mode); (b) $1100{ }^{\circ} \mathrm{C}$; (c) $1200{ }^{\circ} \mathrm{C}$; (d) $1300{ }^{\circ} \mathrm{C}$; (e) $1400{ }^{\circ} \mathrm{C}$.

Figure 6 shows the backscatter electron (BSE) images of specimens sintered at $1300{ }^{\circ} \mathrm{C}$ for different holding times, and the EDS spectrum of the sintered specimens $(60 \mathrm{~min})$. The trend in Figure 6 is similar to that in Figure 5. When the holding time is $60 \mathrm{~min}$, the structure of the specimen is more uniform, as shown in Figure 6c. The WC grains are polygonal or quasi-spherical, and the grain size is $300-500 \mathrm{~nm}$. The sintering temperature $\left(1300^{\circ} \mathrm{C}\right)$ is about $100^{\circ} \mathrm{C}$ lower than that used in traditional sintering processes [21,22], mainly because microwave sintering can reduce the activation energy, accelerate diffusion, and increase the rate of densification [27]. In addition, nanocomposite GGIs have a high solubility and mobility in liquid cobalt, which can prevent the dissolution and growth of the WC particles and further optimise the microstructure of the alloy [28]. Another mechanism causing the aforementioned inhibition is that nanocomposite GGIs segregate to the WC-Co grain boundaries and their triple junctions, which hinders WC grain growth by exerting a pinning force (Zener-drag) on the moving grain boundaries [13]. As shown in Figure 6e, the main components of the selected area are $\mathrm{C}, \mathrm{W}$, and $\mathrm{Co}$, and contain a small amount of $\mathrm{V}, \mathrm{Cr}$, and $\mathrm{O}$. The reason for the presence of a small amount of $\mathrm{O}$ may be that nano-Co powders have high activity and are easily oxidised in air; this may lead to a small amount of Co being oxidised during mixing, moulding, and the like. 

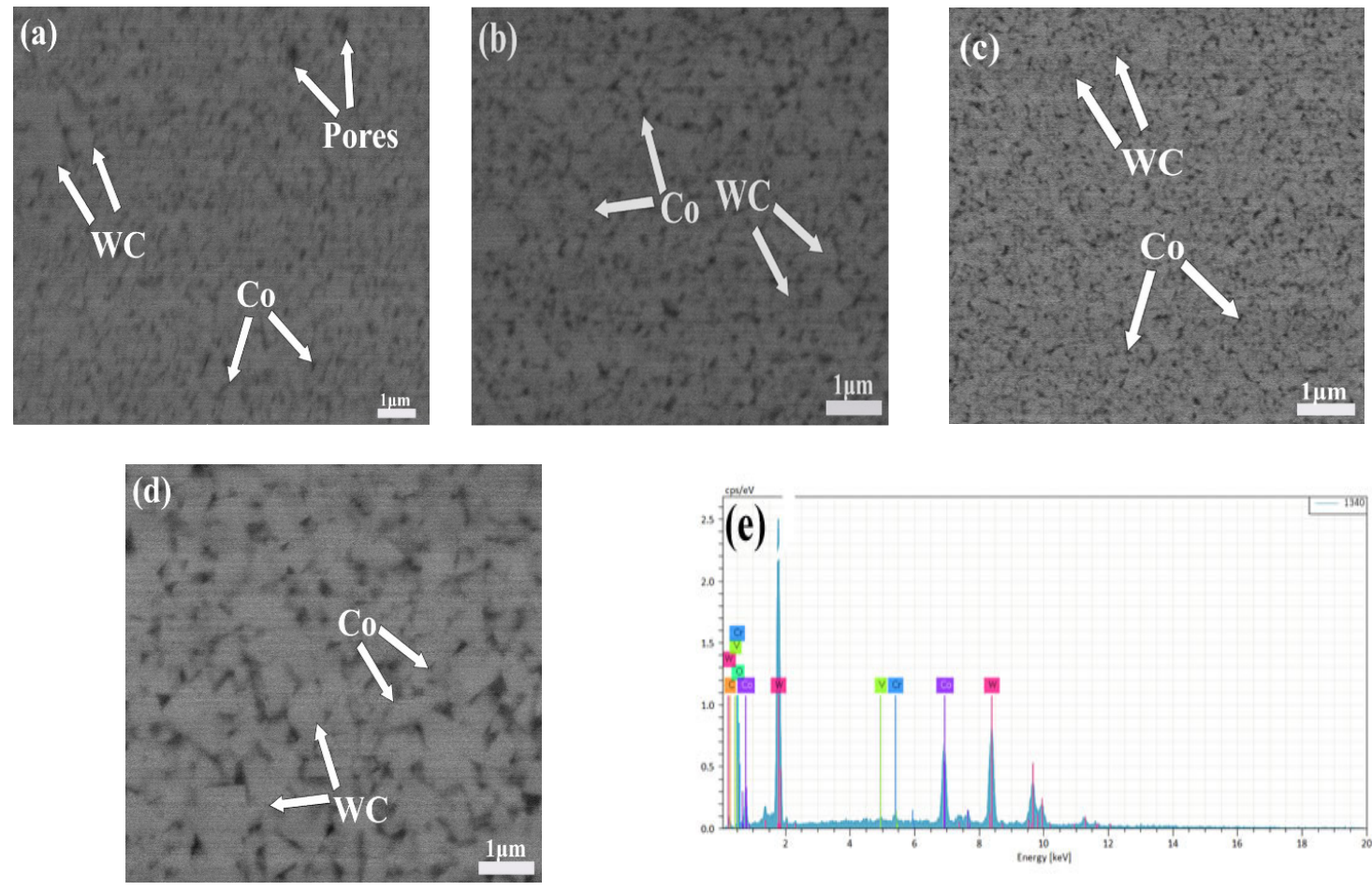

Figure 6. BSE images of specimens sintered at $1300{ }^{\circ} \mathrm{C}$ for different holding times (a) $20 \mathrm{~min}$; (b) $40 \mathrm{~min}$; (c) $60 \mathrm{~min}$; (d) $80 \mathrm{~min}$; (e) EDS spectrum of the sintered specimen (60 min).

Figure 7 and Table 1 show the relative density, Vickers hardness, and fracture toughness of ultrafine cemented carbides at different sintering temperatures $\left(1100,1200,1300\right.$, and $\left.1400{ }^{\circ} \mathrm{C}\right)$ for $40 \mathrm{~min}$.

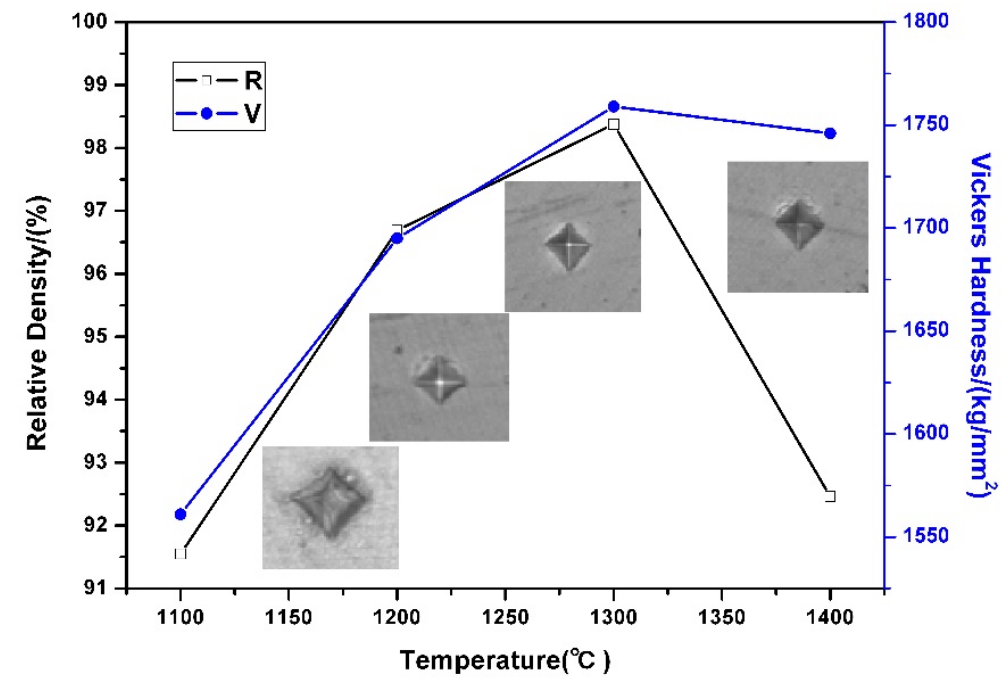

Figure 7. Relative density and Vickers hardness of ultrafine cemented carbides at different sintering temperatures for $40 \mathrm{~min}$.

Figure 7 and Table 1 show that the relative density, Vickers hardness, and fracture toughness of cemented carbide specimens first increase, then decrease with the increasing sintering temperature or prolonged holding time [29]. When the sintering temperature is $1300^{\circ} \mathrm{C}$, the relative density, Vickers hardness, and fracture toughness of the specimen reach the maximum values of $98.38 \%, 1759 \mathrm{~kg} / \mathrm{mm}^{2}$, and $12.2 \mathrm{MPa} \cdot \mathrm{m}^{1 / 2}$, respectively. The hardness and fracture toughness of the $\mathrm{WC}-\mathrm{V}_{8} \mathrm{C}_{7}-\mathrm{Cr}_{3} \mathrm{C}_{2}-\mathrm{Co}$ ultrafine cemented carbides sintered at $1400^{\circ} \mathrm{C}$ decrease (albeit slightly). The main reason for this is 
that, when the sintering temperature reaches $1400{ }^{\circ} \mathrm{C}$, an excess amount of liquid phase is produced, too much WC dissolution and precipitation occurs, and WC grains grow abnormally, resulting in the decrease in hardness and fracture toughness of the specimen. In addition, the relative density of the WC- $\mathrm{V}_{8} \mathrm{C}_{7}-\mathrm{Cr}_{3} \mathrm{C}_{2}-\mathrm{Co}$ ultrafine cemented carbide sintered at $1400{ }^{\circ} \mathrm{C}$ is decreased. This is mainly attributed to the over-burning of the specimen caused by too high a sintering temperature, resulting in swelling and the reduction in the density of the specimen.

Table 1. Fracture toughness of ultrafine cemented carbides at different sintering temperatures for $40 \mathrm{~min}$.

\begin{tabular}{ccccc}
\hline Temperature $\left({ }^{\circ} \mathrm{C}\right)$ & 1100 & 1200 & 1300 & 1400 \\
\hline Fracture Toughness $\left(\mathrm{MPa} \cdot \mathrm{m}^{1 / 2}\right)$ & 9.6 & 10.3 & 12.2 & 11.5 \\
\hline
\end{tabular}

Figure 8 and Table 2 show the relative density, Vickers hardness, and fracture toughness of ultrafine cemented carbides sintered at $1300{ }^{\circ} \mathrm{C}$ for different holding times $(20,40,60$, and $80 \mathrm{~min})$ - the trend is similar to the effect of sintering temperature on the relative density, Vickers hardness, and fracture toughness of the specimens (Figure 7 and Table 1). When the holding time is $60 \mathrm{~min}$, the relative density, Vickers hardness, and fracture toughness of the specimens reach the maximum values of $99.79 \%, 1842 \mathrm{~kg} / \mathrm{mm}^{2}$, and $12.6 \mathrm{MPa} \cdot \mathrm{m}^{1 / 2}$, respectively. This is mainly because the power of the microwave field between the particles is almost 30 times than that of the external field, which leads to the enhancement of surface ionisation. Consequently, the rate of ionic diffusion and ion kinetic energy increases across the entire area, particularly at grain boundaries. This results in the formation of more uniformly distributed grain sizes and a denser body $[17,30]$. When the holding time is prolonged to $80 \mathrm{~min}$, the relative density, Vickers hardness, and fracture toughness of the specimen begin to decrease, which is similar to the decrease in the properties of the specimen caused by the increase in sintering temperature (i.e., to $1400{ }^{\circ} \mathrm{C}$ ).

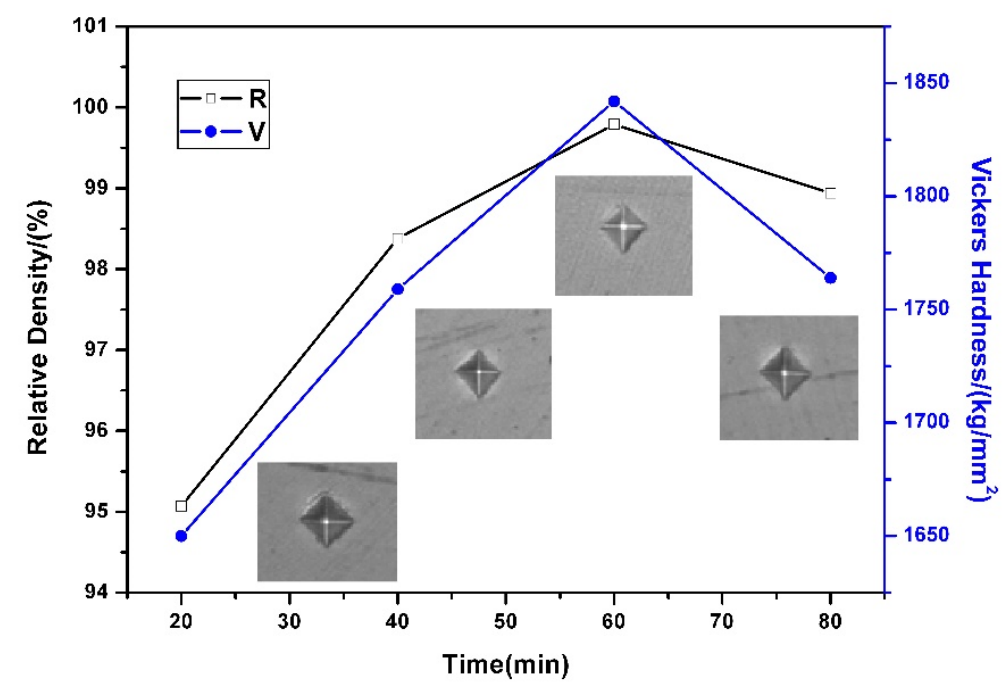

Figure 8. Relative density and Vickers hardness of ultrafine cemented carbides at $1300{ }^{\circ} \mathrm{C}$ for different holding times.

Table 2. Fracture toughness of ultrafine cemented carbides at $1300^{\circ} \mathrm{C}$ for different holding times.

\begin{tabular}{ccccc}
\hline Holding Time $(\mathrm{min})$ & 20 & 40 & 60 & 80 \\
\hline Fracture Toughness $\left(\mathrm{MPa} \cdot \mathrm{m}^{1 / 2}\right)$ & 10.1 & 12.2 & 12.6 & 11.9 \\
\hline
\end{tabular}




\section{Conclusions}

Ultrafine cemented carbides were prepared by microwave sintering using nanocomposites as raw materials. Cemented carbides, with an average grain size of WC of about $300-500 \mathrm{~nm}$, can be obtained after processing at $1300{ }^{\circ} \mathrm{C}$ for $60 \mathrm{~min}$. The relative density, Vickers hardness, and fracture toughness of the specimen reach the maximum values of $99.79 \%, 1842 \mathrm{~kg} / \mathrm{mm}^{2}$, and $12.6 \mathrm{MPa} \cdot \mathrm{m}^{1 / 2}$, respectively. With increasing sintering temperature or prolonged holding time, the number and size of voids on the surface of the specimens decrease gradually, and the mechanical properties of the specimens first increase, and then decrease. Microwave sintering can reduce the activation energy, accelerate diffusion, and increase the degree of densification of the alloy. Nanocomposite GGIs can prevent the dissolution and growth of the WC particles, further optimise the microstructure, and improve the mechanical properties of the alloy. Another mechanism causing this inhibition is such that nanocomposite GGIs segregate to the WC-Co grain boundaries and their triple junctions, which hinders WC grain growth by exerting a pinning force (Zener-drag) on the moving grain boundaries.

Author Contributions: Conceptualization, Y.Q. and Z.Z.; methodology, Z.Z.; software, Y.Q.; validation, Y.Q. and Z.Z.; formal analysis, Y.Q.; investigation, Z.Z.; resources, Y.Q.; data curation, Z.Z.; writing-original draft preparation, Y.Q.; writing-review and editing, Z.Z.; visualization, Y.Q.; supervision, Z.Z.; project administration, Z.Z.; funding acquisition, Z.Z. All authors have read and agreed to the published version of the manuscript.

Funding: This research was funded by the Natural Science Foundation of China (51304063) and the Key Scientific and Technological Research Projects in Henan Province (182102210389), China.

Conflicts of Interest: The authors declare no conflict of interest.

\section{References}

1. García, J.; Ciprés, V.C.; Blomqvist, A.; Kaplan, B. Cemented carbide microstructures: A review. Int. J. Refract. Met. Hard Mater. 2019, 80, 40-68. [CrossRef]

2. Li, C.W.; Chang, K.C.; Yeh, A.C. On the microstructure and properties of an advanced cemented carbide system processed by selective laser melting. J. Alloys Compd. 2019, 782, 440-450. [CrossRef]

3. Li, J.; Cheng, J.; Chen, P.; Chen, W.; Wei, B.; Liu, J. Effects of partial substitution of copper for cobalt on the microstructure and properties of ultrafine-grained WC-Co cemented carbides. J. Alloys Compd. 2018, 735, 43-50. [CrossRef]

4. Al-Aqeeli, N. Characterization of nano-cemented carbide Co-doped with vanadium and chromium carbides. Powder Technol. 2015, 273, 47-53. [CrossRef]

5. Ban, Z.G.; Shaw, L.L. Synthesis and processing of nanostructured WC-Co materials. J. Mater. Sci. 2002, 37, 3397-3403. [CrossRef]

6. Guo, L.; Xiao, L.R.; Zhao, X.J.; Song, Y.F.; Wang, H.J. Preparation of WC/Co composite powders by electroless plating. Ceram. Int. 2017, 43, 4076-4082. [CrossRef]

7. Fang, Z.Z.; Wang, X.; Ryu, T.; Hwang, K.S.; Sohn, H.Y. Synthesis, sintering, and mechanical properties of nanocrystalline cemented tungsten carbide-A review. Int. J. Refract. Met. Hard Mater. 2009, 27, $288-299$. [CrossRef]

8. Yang, Q.; Yang, J.; Wen, Y.; Zhang, Q.; Chen, L.; Chen, H. A novel route for the synthesis of ultrafine WC-15wt \%Co cemented carbides. J. Alloys Compd. 2018, 748, 577-582. [CrossRef]

9. Gao, Y.; Song, X.; Wang, H.; Wang, X.; Liu, X. Effect of carbon content on matching of key crystal planes in nanocrystalline cemented carbide. CrystEngComm 2014, 16, 4935-4939. [CrossRef]

10. Yu, B.; Li, Y.; Lei, Q.; Nie, Y. Microstructures and mechanical properties of WC-Co-xCr-Mo cement carbides. J. Alloys Compd. 2019, 771, 636-642. [CrossRef]

11. Lee, H.R.; Kim, D.J.; Hwang, N.M.; Kim, D.Y. Role of vanadium carbide additive during sintering of WC-Co: Mechanism of grain growth inhibition. J. Am. Ceram. Soc. 2003, 86, 152-154. [CrossRef]

12. Liu, B.; Shi, A.; Su, Q.; Chen, G.; Yang, B. Recovery of tungsten carbides to prepare the ultrafine WC-Co composite powder by two-step reduction process. Powder Technol. 2017, 306, 113-119. [CrossRef]

13. Farag, S.; Konyashin, I.; Ries, B. The influence of grain growth inhibitors on the microstructure and properties of submicron, ultrafine and nano-structured hardmetals-A review. Int. J. Refract. Met. Hard Mater. 2018, 77, 12-30. [CrossRef] 
14. Chuvil'Deev, V.N.; Moskvicheva, A.V.; Lopatin, Y.G.; Blagoveshchenskii, Y.V.; Isaeva, N.V.; Mel'Nik, Y.I. Sintering of WC and WC-Co nanopowders with different inhibitor additions by the SPS method. Dokl. Phys. 2011, 56, 114-117. [CrossRef]

15. Zhao, C.N.; Zhang, J.J.; Li, Y.; Meng, X.; Li, H.B. Microwave-assisted extraction of phenolic compounds from melastoma sanguineum fruit: Optimization and identification. Molecules 2018, 23, 2498. [CrossRef]

16. Jin, K.; Jia, Y.B.; Zhao, Z.W.; Song, W.Q.; Wang, S.; Guan, C.L. Synthesis of chromium carbide nanopowders by nicrowave heating and their composition and microstructure change under gamma ray irradiation. Molecules 2019, 24, 16. [CrossRef]

17. Alem, S.A.A.; Latifi, R.; Angizi, S.; Hassanaghaei, F.; Aghaahmadi, M.; Ghasali, E.; Rajabi, M. Microwave sintering of ceramic reinforced metal matrix composites and their properties: A review. Mater. Manuf. Process. 2019, 35, 303-327. [CrossRef]

18. Cai, W.; Gao, R.; Fu, C.; Yao, L.; Chen, G.; Deng, X.; Wang, Z.; Cao, X.; Wang, F. Microstructure, enhanced electric and magnetic properties of $\mathrm{Bi}_{0.9} \mathrm{La}_{0.1} \mathrm{FeO}_{3}$ ceramics prepared by microwave sintering. J. Alloys Compd. 2019, 774, 61-68. [CrossRef]

19. Zhao, Z.W.; Chen, F.X.; Wang, M.C.; Zheng, H.J. Synthesis of chromium carbide nanopowders via a microwave heating method. Int. J. Refract. Met. Hard Mater. 2015, 51, 212-215. [CrossRef]

20. Shetty, D.; Wright, I.; Mincer, P. Indentation fracture of WC-Co cermets. J. Mater. Sci. 1985, 20, $1873-1882$. [CrossRef]

21. Acchar, W.; Gomez, U.U.; Kaysser, W.A.; Goring, J. Strength degradation of a tungsten carbide-cobalt composite at elevated temperatures. Mater. Charact. 1999, 43, 27-32. [CrossRef]

22. Ungar, T.; Borbely, A. Particle-size, size distribution and dislocations in nanocrystalline tungsten-carbide. Nanostruct. Mater. 1999, 11, 103-113. [CrossRef]

23. Freeman, S.A.; Booske, J.H.; Cooper, R.F. Microwave field enhancement of charge transport in sodium chloride. Phys. Rev. Lett. 1995, 74, 2042-2045. [CrossRef]

24. Chen, H.; Yang, Q.; Yang, J.; Yang, H.; Chen, L.; Ruan, J.; Huang, Q. Effects of $\mathrm{VC} \mathrm{Cr}_{3} \mathrm{C}_{2}$ on WC grain morphologies and mechanical properties of WC-6wt.\%Co cemented carbides. J. Alloys Compd. 2017, 714, 245-250. [CrossRef]

25. Zhao, Z.W.; Zheng, H.J.; Liu, S.J.; Shen, J.H.; Song, W.Q.; Chen, J.S. Low temperature synthesis of chromium carbide $\left(\mathrm{Cr}_{3} \mathrm{C}_{2}\right)$ nanopowders by a novel precursor method. Int. J. Refract. Met. Hard Mater. 2015, 48, 46-50. [CrossRef]

26. Loginov, P.A.; Levashov, E.A.; Kurbatkina, V.V.; Zaitsev, A.A.; Sidorenko, D.A. Evolution of the microstructure of Cu-Fe-Co-Ni powder mixtures upon mechanical alloying. Powder Technol. 2015, 276, 166-174. [CrossRef]

27. Charmond, S.; Carry, C.P.; Bouvard, D. Densification and microstructure evolution of Y-Tetragonal zirconia polycrystal powder during direct and hybrid microwave sintering in a single-mode cavity. J. Eur. Ceram. Soc. 2010, 30, 1211-1221. [CrossRef]

28. Grasso, S.; Poetschke, J.; Richter, V.; Maizza, G.; Sakka, Y.; Reece, M.J. Low-temperature spark plasma sintering of pure nano WC powder. J. Am. Ceram. Soc. 2013, 96, 1702-1705. [CrossRef]

29. Laptev, A.V. Structure and properties of WC-Co alloys in solid-phase sintering. I. Geometrical evolution. Powder Metall. Metal C+ 2007, 46, 415-422. [CrossRef]

30. Chadha, R.K.; Singh, A.P.; Singh, K.L.; Sharma, C.; Naithani, V. Influence of microwave processing and sintering temperature on the structure and properties of Sr/Zr doped hydroxyapatite. Mater. Chem. Phys. 2019, 223, 319-324. [CrossRef]

(C) 2020 by the authors. Licensee MDPI, Basel, Switzerland. This article is an open access article distributed under the terms and conditions of the Creative Commons Attribution (CC BY) license (http://creativecommons.org/licenses/by/4.0/). 